\title{
Effects of Visual and Auditory Response Times in Males and Females by using Tactile and Mouse on Web Based Environment
}

\author{
Muhammad Suhaib
}

\begin{abstract}
The purpose of this research work is to find out whether one of visual response time or auditory response time is faster than another on web based environment. Simple reaction time can be strong when an individual is asked to press a button as soon as a light or sound appears. A tool for capturing response times is created. This tool is a web application www.responsetime.muhammadsuhaib.com that runs on server and can be accessed through internet. $R$ is commonly used in countless scientific disciplines for statistical analysis. Collected data will be analyzed by using $R$. it is concluded that on web based environment visual response times are not different than auditory response time. The data are also classified by gender to compare male response time and female response time, data analyzed based on gender, on visual stimuli, male react faster than female. However, on auditory stimuli, there is no different between male and female.
\end{abstract}

Keywords: Response Time, Visual Stimuli, Auditory Stimuli, Web Based Environment, Visual and Audio Response

\section{INTRODUCTION}

Human Response Time works by a nervous system acknowledge the stimulus. The neurons then communicate the message to the brain. The message then journeys from the brain to the spinal cord, which then arrived person's hands and fingers. The motor neurons then communicate the fingers and hands how to react. Reaction time (RT) constrained by the rate of signal broadcast and it's a measure of the response to a stimulus. Response Time plays a very significant role in our lives as its practical implications may be of great consequences. obviously there are some important factors that can affect the average human Reaction Time include left and right hand, age vision, fasting fatigue exercise personality types and intelligence as well. Assumptions about intelligence managing drawn from RT are frequently made with consideration of assignment tentative design, boundaries in measurement skills and mathematical modeling. relationship amid reaction time and Intelligence quotient (IQ) marks includes a significant part of theoretical information processing approaches.

Manuscript published on 30 September 2019

* Correspondence Author

Muhammad Suhaib*, Sr Full Stack Developer, T-Mark Inc., Tokyo, Japan Ph.D. Scholar

(C) The Authors. Published by Blue Eyes Intelligence Engineering and Sciences Publication (BEIESP). This is an open access article under the CC-BY-NC-ND license http://creativecommons.org/licenses/by-nc-nd/4.0/

\section{LITRATURE REVIEW}

Reaction time (RT) is the elapsed time between the presentation of a sensory stimulus and the subsequent behavioral response. In psychometric psychology it is considered to be an index of speed of processing. [1] Human Computer Interaction focusing on the design of computer technology and interaction between computers and humans, Touch Screen Technology like Tilt or Touch increasing day by day specially Smartphones and tablets, playing racing games with both controls. Some users prefer to use tilt control while others feel more convenience to use touch control. users argue that their method of control is better than another. [2] Simple reaction time can be determined when an individual is asked to press a button as soon as a light or sound appears. A research done by Shelton and Kumar shows that the auditory reaction time is faster than the visual reaction time. And also males have faster reaction times when compared to females for both auditory as well as visual stimuli. [3] User response time, in case of human computer interaction, is how fast users react to particular computer output by doing an action. Time is calculated from the beginning of the presence of stimuli until the end of the response act of the user. [4] Playing video games is discussed since last 40 years, Video games is huge educational potential, and similar popular in every age of group, this report evaluate of playing Video Game on computer with keyboard control, Power Law of Practice is use to predict learning curve of the new Tetris game. [5] Previous researches usually use desktop application as tool for measuring the response time. The purpose of this study is to compare the response time on web based application, with all of its advantages and disadvantages.

\section{SHAPIRO-WILK TEST}

The Shapiro-Wilk test, proposed in 1965, The Shapiro-Wilk test is a test for usual spreading displaying high power, leading to decent results even with a little number of observations. In difference to other assessment tests the Shapiro-Wilk is only appropriate to check for normality. 


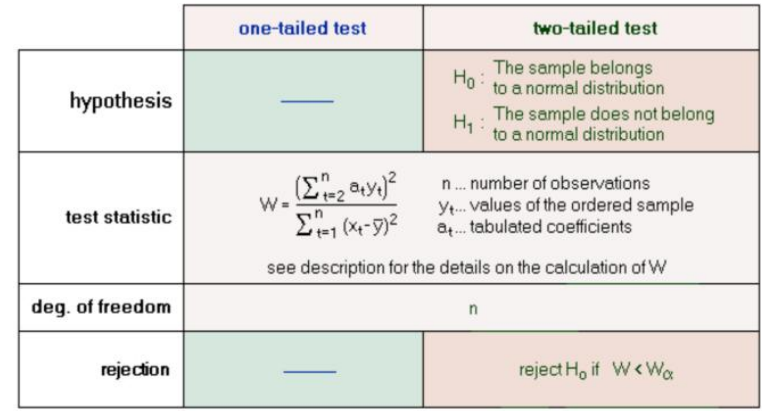

Figure 1. Shapiro-Wilk Tailed Test (Source Shapiro-Wilk)

The fundamental idea behind the Shapiro-Wilk test is to estimation the inconsistency of the sample in two ways: First is the regression line in the QQ Plot allows to approximation the inconsistency, and Second is the inconsistency of the sample can also be observed as an estimator of the people variance. Both can assess values must almost equal in the case of a normal distribution and would result in a quotient of close to 1 . If the quotient is significantly lower than 1 afterward the null hypothesis must be rejected.

\section{TACTILE DEVICES}

Tactile devices transport sensations like vibration, pressure, heat, motion and static electricity to the fingertips of their users. Typically, there is no physical response when pressing a button shown on the touchscreen of a smartphone making it difficult for the user to determine whether their input has been registered by the device.

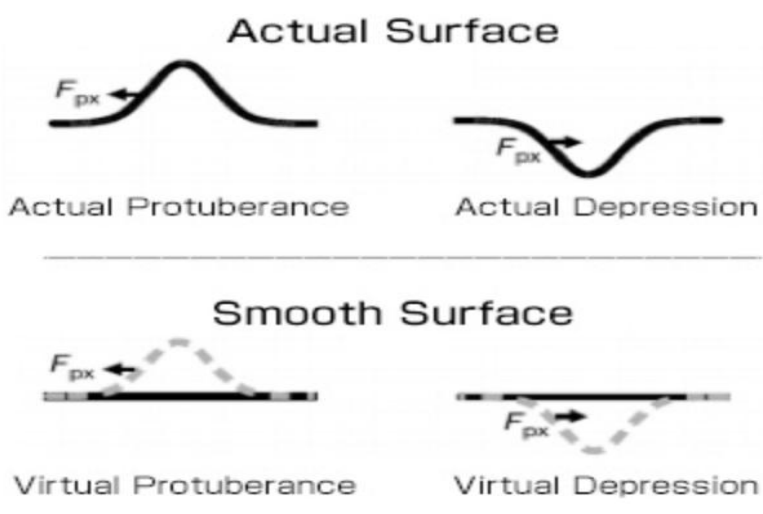

Figure 2. Tactile Actual and Smooth Surface

This problem can be solved by the use of tactile devices that recreate the feeling of pressing an actual button by making the screen vibrate when pressed. Furthermore, by changing the way that the vibration is transferred to the user depending on which area of the screen is pressed it becomes possible for the user to distinguish between multiple buttons displayed on the same screen. Tactile texture is the real thing. It is the actual way a surface feels when it is felt or touched, such as rough, smooth, soft, hard, silky, slimy and sticky. Furthermore, methods of producing complex and distinct touch sensations through different ways of vibration are currently also being researched.

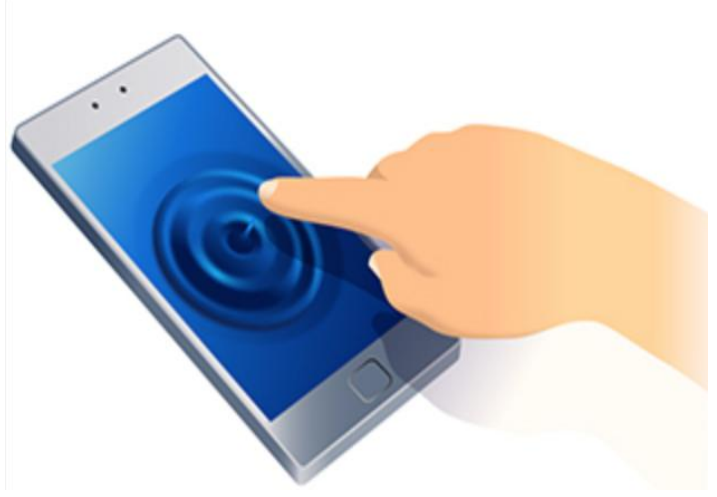

Figure 3. Tactile Illustration (Source Wikipedia)

The sensation of pressing a physical button can be simulated by tactile devices. With the latest technology, more advanced sensations, such as the feeling of clicking or the feeling of a rough surface, can be realized as well.

\section{METHODOLOGY}

www.responsetime.muhammadsuhaib.com A tool for capturing response times is created. This tool is a web application that runs on server and can be accessed through internet.

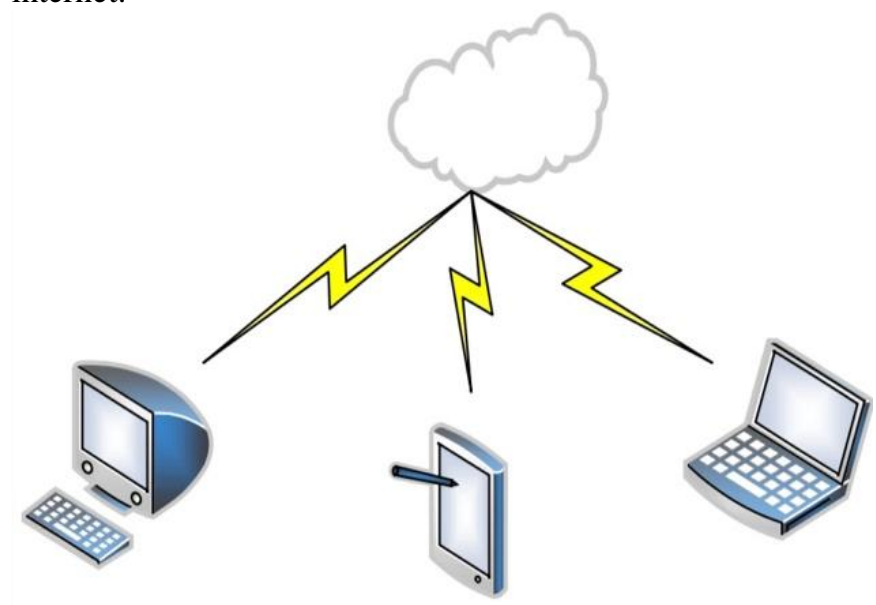

Figure. 4. Online Tool

The speed of our responses play a large part in our everyday life. Immediate reaction times can make big reward, for example, like saving a blistering soccer ball from entering the goal. Slow reaction times may come with consequences. User can record their visual and auditory response time by doing simple test online. The advantages are user can access it whenever and wherever they want. Secondly, we can get massive data from user around the world. However, this approach has many disadvantages.

First, the web application architecture divides the processes into 2 main part, server side and client side. It needs time for server to communicate with client or browser, and vice versa. Another disadvantage is that the client side environment cannot be predicted, especially their browser technology. To deal with this situation, in order to minimize the disadvantages, all processes related to the response time's test are run in client side. 
This will ensure the precise calculation of response time. In trade off, user environment should have been adopting the latest web technology to run the test properly. In the test, to get the visual response time, users have to click a colored shape as fast as the shape appears.

The response time is calculated from the beginning of shape drawn on screen to the time user click the shape. This action will be repeated 5 times and then the average of the response times calculated. The delay time from one shape to another is randomized so users cannot predict when the shape appears. On auditory response time, the procedure of test is practically the same. Users need to measure their response time 5 iterations and the delay time from one sound to another is also randomized.

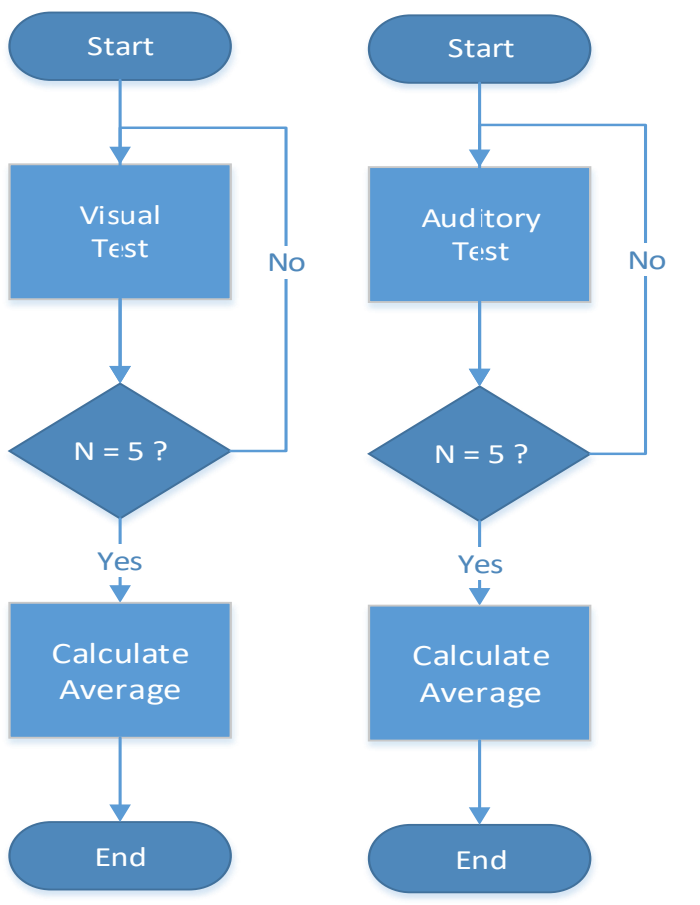

Figure 5. Flowchart of Visual and Auditory Test

Collected data will be analyzed using $\mathrm{R}$. $\mathrm{R}$ is a free software environment for statistical computing and graphics. It compiles and runs on a wide variety of UNIX platforms, Windows and Mac OS. [3]

\section{DATA AND ANALYSIS}

Data is collected after inviting participants 19 male and 15 female students physically normal, without any hearing or visual disorder in the age group 17-34 years were studied in Tokyo, Japan.

\begin{tabular}{|r|l|l|r|r|}
\hline No & Gender & Device & \multicolumn{1}{|c|}{ RT (s) } & \multicolumn{1}{l|}{ RT (s) } \\
\hline 1 & male & tactile & 0.672 & 0.753 \\
\hline 2 & male & mouse & 0.708 & 0.534 \\
\hline 3 & male & tactile & 0.623 & 0.592 \\
\hline 4 & female & tactile & 0.828 & 1.138 \\
\hline
\end{tabular}

\begin{tabular}{|c|c|c|c|c|}
\hline 5 & male & mouse & 0.502 & 0.35 \\
\hline 6 & male & tactile & 0.709 & 1.956 \\
\hline 7 & male & mouse & 0.795 & 0.979 \\
\hline 8 & male & tactile & 0.964 & 4.616 \\
\hline 9 & female & tactile & 2.839 & 0.919 \\
\hline 10 & male & tactile & 0.783 & 2.185 \\
\hline 11 & female & mouse & 0.527 & 0.595 \\
\hline 12 & female & tactile & 0.769 & 3.515 \\
\hline 13 & male & tactile & 0.858 & 0.808 \\
\hline 14 & female & tactile & 0.535 & 0.524 \\
\hline 15 & male & tactile & 0.783 & 2.185 \\
\hline 16 & male & mouse & 0.537 & 0.578 \\
\hline 17 & male & mouse & 0.702 & 0.692 \\
\hline 18 & male & mouse & 0.707 & 0.672 \\
\hline 19 & male & mouse & 0.627 & 0.679 \\
\hline 20 & male & mouse & 0.705 & 0.646 \\
\hline 21 & male & mouse & 0.642 & 0.715 \\
\hline 22 & male & mouse & 0.451 & 0.715 \\
\hline 23 & female & tactile & 2.301 & 3.931 \\
\hline 24 & male & mouse & 0.293 & 0.219 \\
\hline 25 & female & mouse & 0.812 & 0.65 \\
\hline 26 & female & mouse & 1.042 & 0.731 \\
\hline 27 & female & mouse & 0.968 & 0.697 \\
\hline 28 & female & tactile & 0.675 & 0.549 \\
\hline 29 & female & mouse & 1.061 & 0.821 \\
\hline 30 & female & mouse & 1.048 & 0.933 \\
\hline 31 & female & tactile & 0.808 & 2.61 \\
\hline 32 & male & mouse & 0.753 & 0.759 \\
\hline 33 & female & tactile & 0.756 & 0.693 \\
\hline 34 & female & mouse & 0.748 & 0.739 \\
\hline
\end{tabular}

Users are more preferred using mouse on computer to do the test rather than using smart phone or pad. Mouse is used by 19 users, while users using tactile are 15 .
Published By:

Blue Eyes Intelligence Engineering \& Sciences Publication 


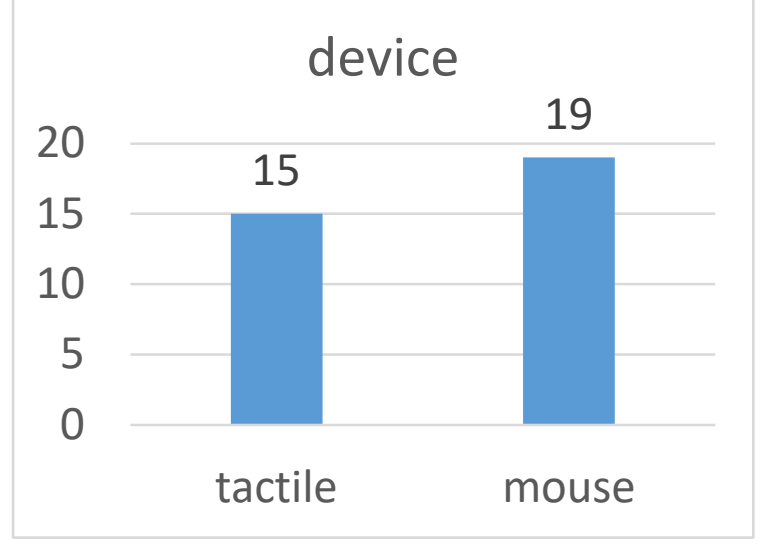

Figure 6. Device used on test

For better understanding of characteristics of the data, a test for normal distribution is needed. First, excluding the gender, visual response time and auditory response time will be analyzed in order to determine are they normally distributed or not. To do this, density, quantile-quantile test and Shapiro-Wilk normality test are applied. Kernel density plots are usually a much more effective way to view the distribution of a variable.

[4] The quantile-quantile (q-q) plot is a graphical technique for determining if two data sets come from populations with a common distribution. [5] The Shapiro-Wilk test utilizes the null hypothesis principle to check whether a sample $\mathrm{x} 1, \ldots$, xn came from a normally distributed population. [6]

Here is the result of distribution of visual response time.

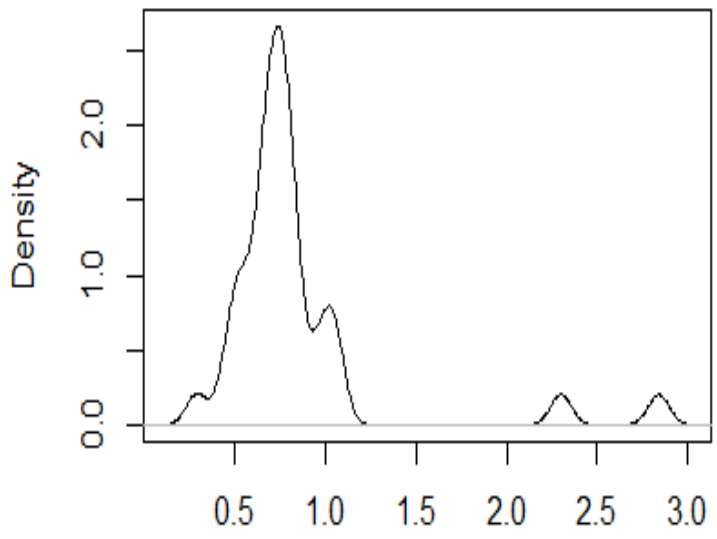

$$
\mathrm{N}=34 \text { Bandwidth }=0.05789
$$

Figure 7. Visual RT data density

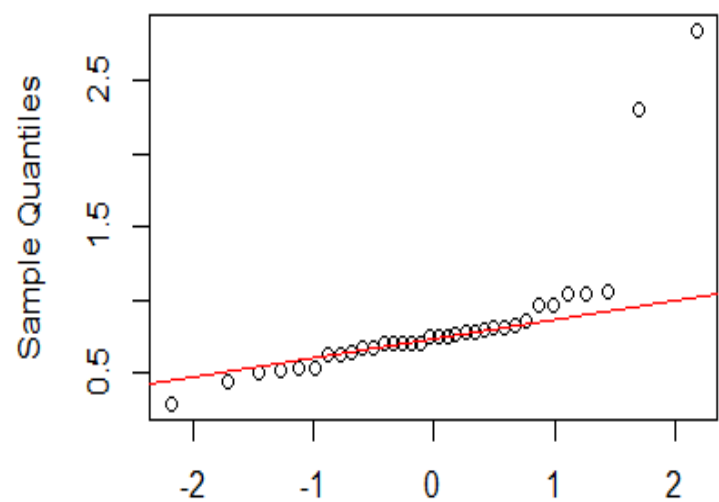

Theoretical Quantiles

Figure 8. Visual RT data QQ Normal Plot

Shapiro-Wilk normality test on Visual RT data produce the value of $\mathrm{W}=0.60518$ and $\mathrm{p}$-value $=2.288 \mathrm{e}-08$.

Regarding the fact of density plot, quantile-quantile normal plot and the result of Shapiro-Wilk test, Visual RT data is not normally distributed.

Moving on to auditory response time data. Here is the result.

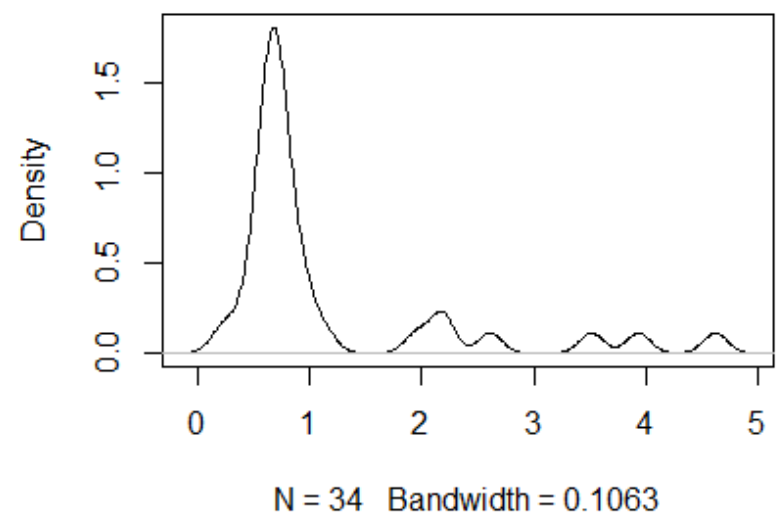

Figure 9. Auditory RT data density

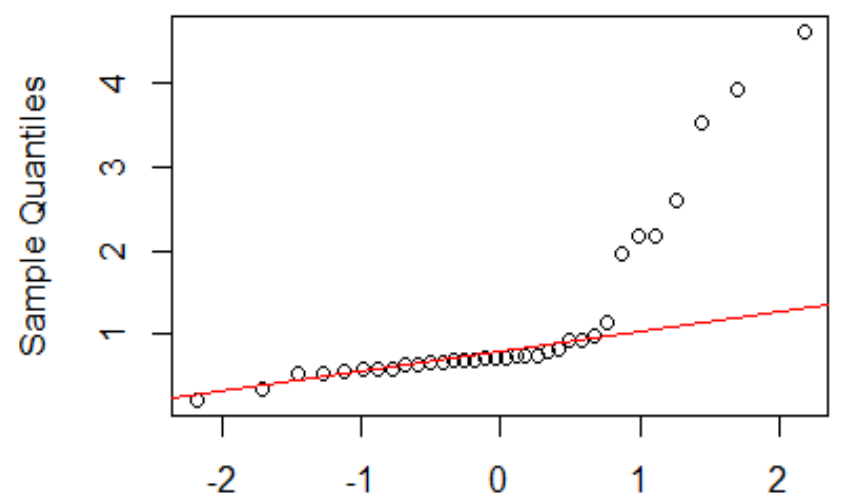

Theoretical Quantiles

Figure 10. Auditory RT data QQ Normal Plot

Published By: 
Shapiro-Wilk normality test on Auditory RT data produce the value of $\mathrm{W}=0.6684$ and $\mathrm{p}$-value $=1.668 \mathrm{e}-07$.

From above 3 (three) facts, it can be said that Auditory RT data is not normally distributed.

To compare this 2 (two) non-normal distributed data, non-parametric analysis is used. Non parametric analysis use no assumptions whether distribution normal or not so it is suitable to be applied in this case.

Method used to compare Visual RT and Auditory RT is Wilcoxon Signed Rank test. The Wilcoxon signed-rank test is a non-parametric statistical hypothesis test used when comparing two related samples, matched samples, or repeated measurements on a single sample to assess whether their population mean ranks differ. [7]

Before analyzing data using Wilcoxon Signed Rank test, it is better to look into the box plot of the data. Box plot provide basic information about a distribution. Box plots are good at portraying extreme values and are especially good at showing differences between distributions. [8]

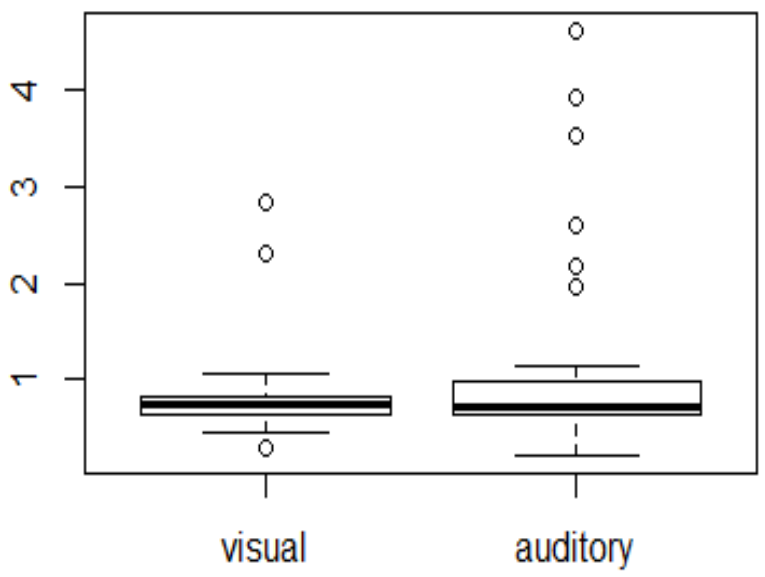

Figure 11. Boxplot of Visual RT and Auditory RT

Before conducting the two-sided nonparametric test using the " Wilcox Test" command in R, Null Hypothesis need to be determined first. For this case, null hypothesis is that the median of visual response time is not different with median of auditory response time.

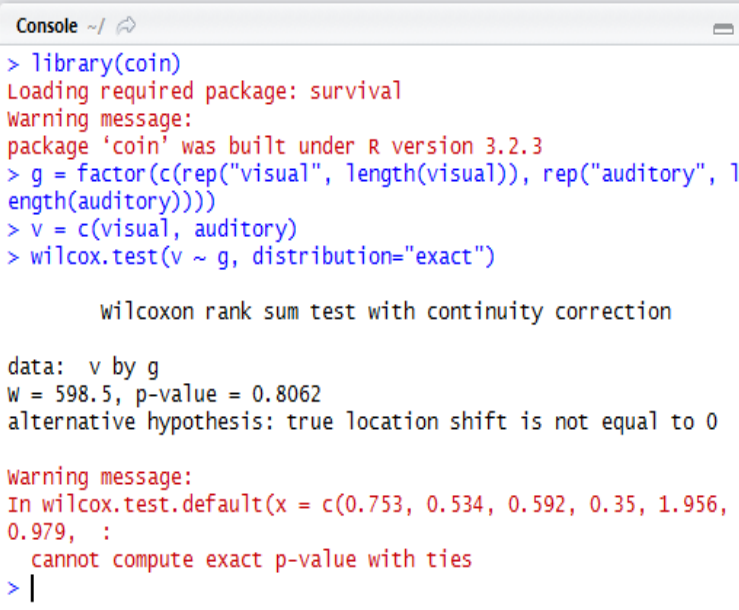

Figure 12. Wilcoxon Signed Rank test for Visual-Auditory
Based on previous result of Wilcoxon Signed Rank test on $\mathrm{R}$, p-value is bigger than 0.05 , so the null hypothesis cannot be rejected.

Next analysis is dividing data through gender. So, data is also checked for its distribution.

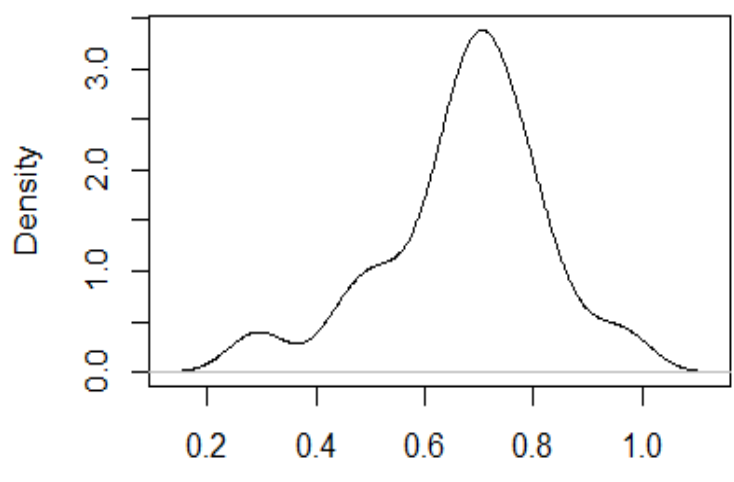

$\mathrm{N}=19$ Bandwidth $=0.0533$

Figure 13. Male visual RT data density

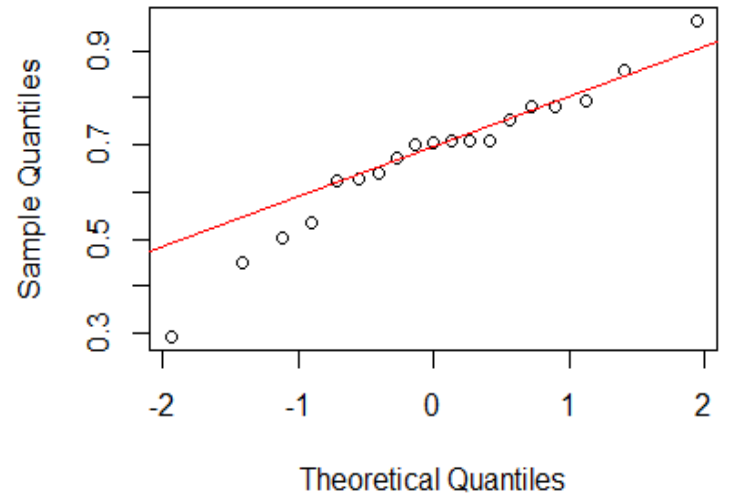

Figure 14. Male visual RT data QQ Normal Plot

Shapiro-Wilk normality test on male visual response time data produce the value of $\mathrm{W}=0.95413$ and $\mathrm{p}$-value $=$ 0.4631 .

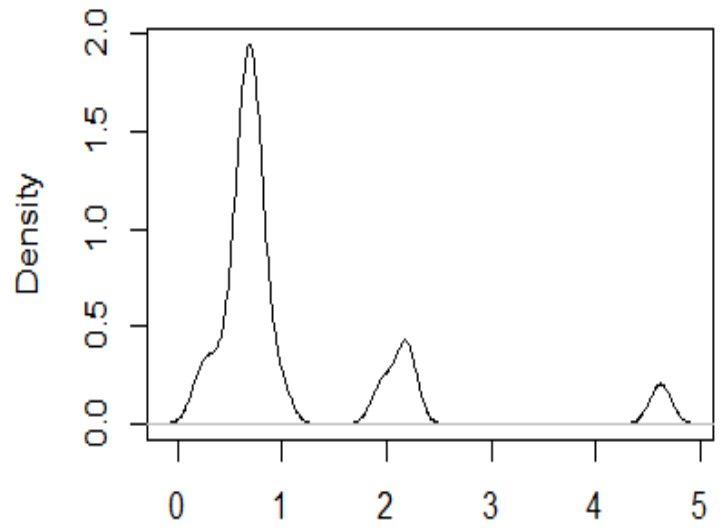

$\mathrm{N}=19$ Bandwidth $=0.1023$

Figure 15. Male Auditory RT data density

Published By:

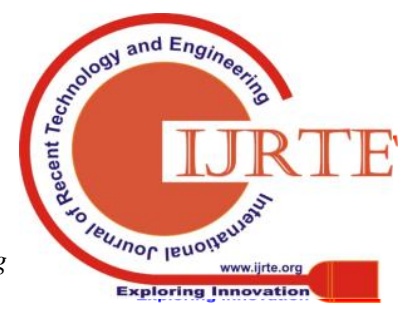




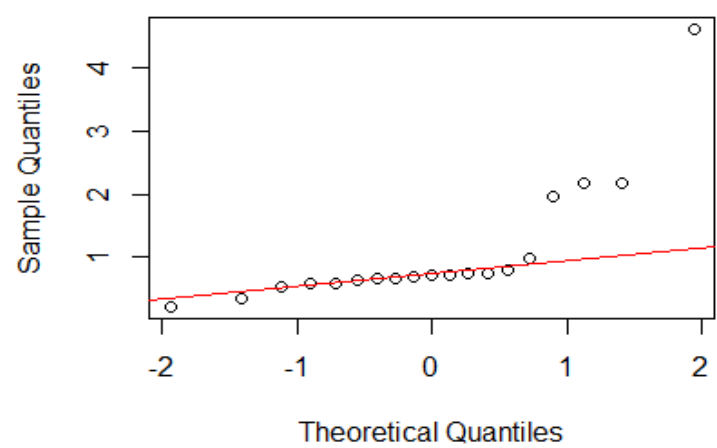

Figure 16. Male Auditory RT data QQ Normal Plot

Shapiro-Wilk normality test on male auditory response time data produce the value of $\mathrm{W}=0.64855$ and $\mathrm{p}$-value $=$ $1.44 \mathrm{e}-05$.

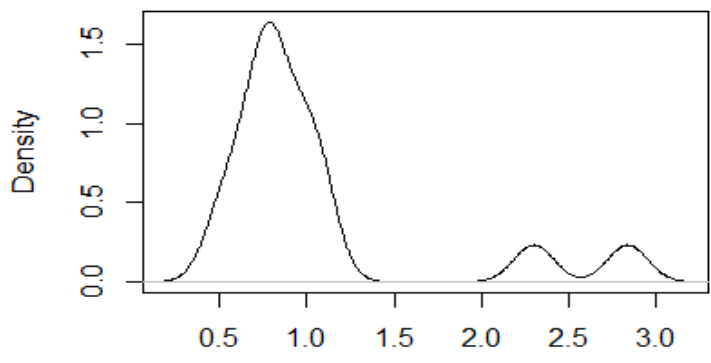

$\mathrm{N}=15$ Bandwidth $=0.1145$

Figure 17. Female visual RT data density

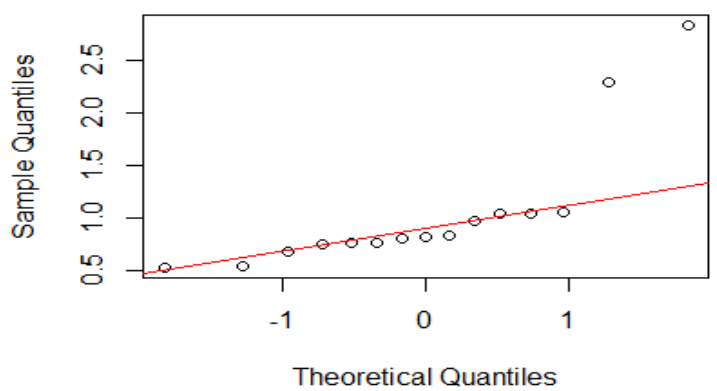

Figure 18. Female visual RT data QQ Normal Plot

Shapiro-Wilk normality test on female visual response time data produces the value of $\mathrm{W}=0.67069$ and $\mathrm{p}$-value $=$ 0.0001228

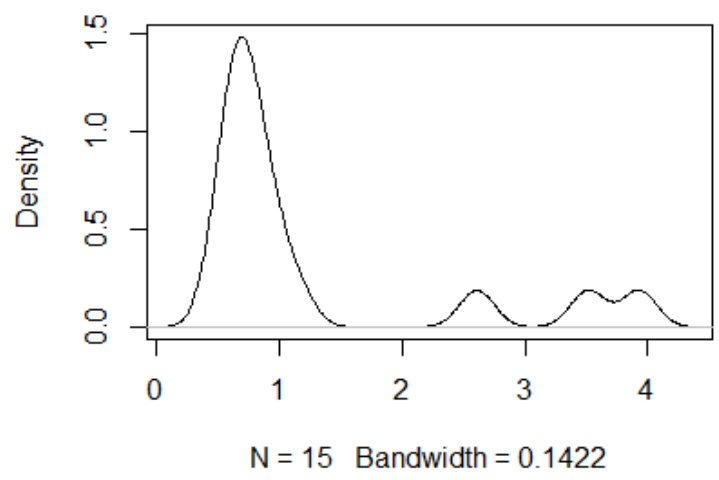

Figure 19. Female Auditory RT data density

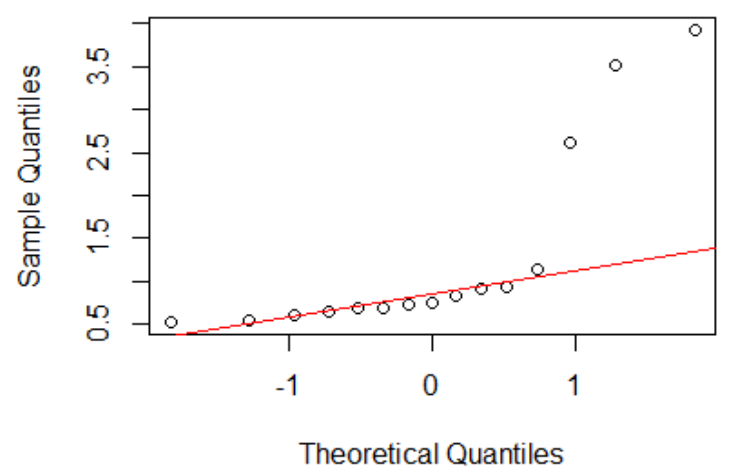

Figure 20. Female Auditory RT data QQ Normal Plot

Shapiro-Wilk normality test on female auditory response time data produces the value of $\mathrm{W}=0.65404$ and $\mathrm{p}$-value $=$ 8.352e-05.

Based on density of data, Quantile-Quantile Normal Plot and the result of Shapiro-Wilk normality test, above data are said to be non-normal distribution data.

Comparing the male visual RT and female visual RT, Mann-Whitney $U$ test is used. Mann-Whitney $U$ test is a non-parametric method appropriate for examining the difference in Median for 2 independent populations. Null hypothesis is determined as there is no difference between male visual response time and female visual response time.

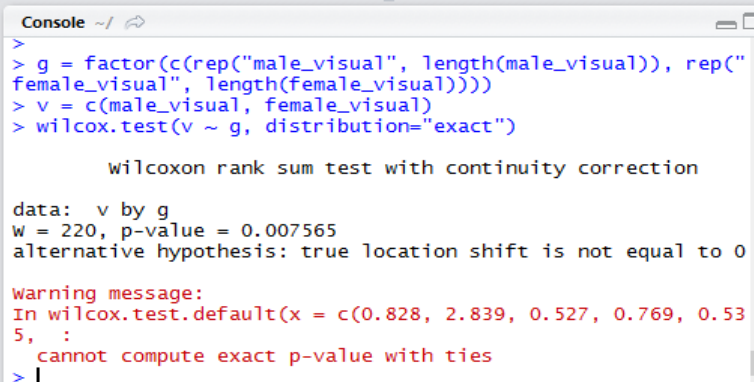

Figure 21. Mann-Whitney $U$ test result on male visual and female visual

The result says that there is enough evidence to say that male visual response time is different than female response time. With mean of male visual response time is 0.6744211 and mean of female visual response time is 1.0478, it can be said that on the case of visual stimuli, male response faster than female.

Comparing male auditory RT and female auditory RT with null hypothesis stated as there is no difference between male auditory response time and female auditory response time. 


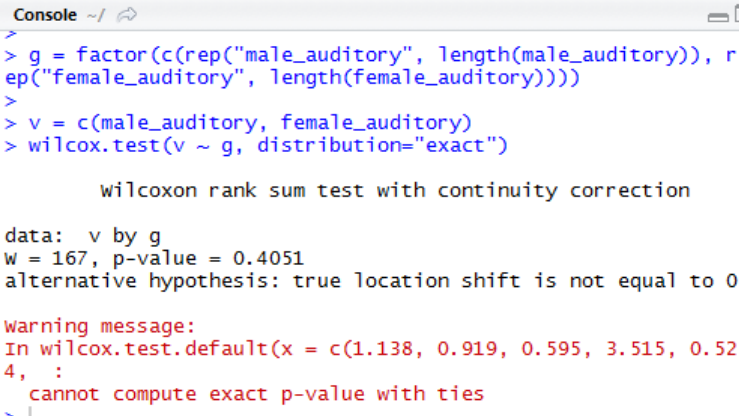

Figure 22. Mann-Whitney $U$ test result on male visual and female visual

From the result above, with p-value bigger than 0.05 , there is no enough evidence to reject the null hypothesis. CONCLUSION

Several studies have determined that the mean auditory reaction time is faster than the mean visual reaction time. This means you will react quicker to a sound than you would a light. The small explanation is that sound takes less time to reach the brain than does visual information. Several other studies have concluded that men have faster auditory reaction times than women. The precise reason is unknown, but supposing has been made that the reaction time is influenced by different cognitive strategies employed by females. From data and analysis above, it can be concluded that on web based environment visual response times are not different than auditory response time. But if the data analyzed based on gender, on visual stimuli, male react faster than female. However, on auditory stimuli, there is no different between male and female.

\section{FUTURE WORKS}

Creating tool for measure response time on web based environment is a hard work. Still, some elements of this web application need to be perfected. Technologies used by this application are state of the arts to ensure the precise of measurements but in trade off with the compatibility of old browser. It is needed to find how to measure response time accurately but still compatible and work like a charm in all browser. Device category in this research is used to inform about the percentage of the usage only. It can be improved to explore whether using particular device can give different response time or not.

\section{ACKNOWLEDGMENT}

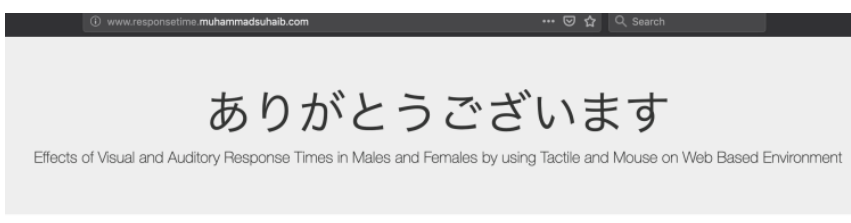

Thank You So Much For Your Time and Participation Please Freely Contact Me If You Have Any Questions

\section{Muhammad Suhailb}

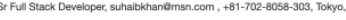

\section{REFERENCES}

1. Jensen, A. R. (2006). Clocking the mind: Mental chronometry and individual differences. Amsterdam: Elsevier. (ISBN 978-0-08-044939-5)

2. Suhaib, Muhammad, Tilt or Touch? An Evaluation of Steering Control of Racing Game on Tablet or Smartphone (September 1, 2018).
International Journal of Innovative Research in Computer and Communication Engineering, Vol. 6, Issue 9, September 2018 Available at SSRN: https://ssrn.com/abstract=3409575 or http://dx.doi.org/10.2139/ssrn.3409575

3. Shelton, Jose and Kumar, Gideon Praven. (2010). "Comparison between Auditory and Visual Simple Reaction Times", Neuroscience \& Medicine, volume 1, page 30-32

4. $\quad$ https://www.r-project.org, 2016

5. Suhaib, Muhammad, A Study of Playing Video Game on Computer with Keyboard Control (September 30, 2018). International Research Journal of Engineering and Technology (IRJET) Volume 5, Issue 10 (Oct 2018). Available at SSRN: https://ssrn.com/abstract=3409536 or http://dx.doi.org/10.2139/ssrn.3409536

6. http://www.statmethods.net/graphs/density.html, 2016

7. http://www.itl.nist.gov/div898/handbook/eda/section3/qqplot.htm, 2016

8. https://en.wikipedia.org/wiki/Shapiro\%E2\%80\%93Wilk test, 2016

9. https://en.wikipedia.org/wiki/Wilcoxon_signed-rank_test, 2016

10. http://onlinestatbook.com/2/graphing distributions/boxplots.html, 2016

11. Suhaib, Muhammad, A Study of the Learning Curve of the Japanese Keyboard on Smartphone (September 25, 2018). International Journal of Scientific Research \& Engineering Trends, Volume 4, Issue 5, Sept-Oct-2018. Available at SSRN: https://ssrn.com/abstract=3409538 or http://dx.doi.org/10.2139/ssrn.3409538

12. Suhaib, Muhammad and Ohnishi, Atsushi, Potential Conflicts Identification among Sub Goals in Goal Oriented Requirement Analysis Using Matrix (September 10, 2018). International Journal of Progressive Sciences and Technologies (IJPSAT), Vol. 10 No. 2 September 2018 Available at SSRN: https://ssrn.com/abstract=3409547

\section{AUTHORS PROFILE}

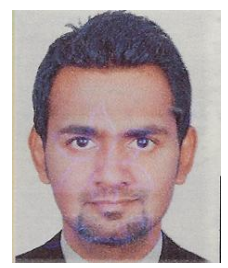

Muhammad Suhaib, Working as Sr. Full Stack Developer at T-Mark Inc., Tokyo, JP, Experienced Software Engineer with a demonstrated history of working in the information technology and services industry. Born 1988 in Pakistan, Pursuing double Doctoral Degree Major in Computer Science and Information System Management,, Graduated from Department of Advanced Information Science and Engineering, Master of Engineering, Ritsumeikan University, Japan, Graduated from Department of Computer Science, Bachelor of Science Computer Science, Dadabhoy Institute of Higher Education, Graduated from Faculty of Education, Bachelor of Education Preston University,, Graduate from Faculty of Arts, Bachelor of Arts, University of Karachi, Pakistan. 